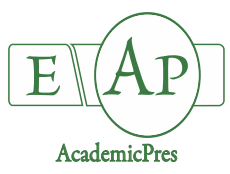

Zhu H et al. (2021)

Notulae Botanicae Horti Agrobotanici Cluj-Napoca

Volume 49, Issue 1, Article number 12193

DOI: $10.15835 /$ nbha49112193

Research Article

\title{
The use of un-composted spent mushroom residue as a replacement of peat in substrates for Gossypium herbaceum and Talinum paniculatum
}

\section{He ZHU, Shujie ZHAO, Anan JIN, Jingyao TANG, Yunqing LUO*}

\author{
Jilin Agricultural University, College of Resources and Environment, Changchun, 130118, China; \\ zhuhe311@jlau.edu.cn; sjzhaom@163.com;17843097757@163.com; jytang777@163.com; \\ luoyq@jlau.edu.cn ("corresponding author)
}

\begin{abstract}
In order to evaluate the effect of growing media with peat and spent mushroom residue (SMR) on medicinal plants, we cultured Gossypium herbaceum and Talinum paniculatum seedlings in the substrates with SMR in proportions of $0 \%$ (control), $25 \%, 50 \%, 75 \%$, and $100 \%$. Results showed that $G$. herbaceum seedlings can survive in all treatments, but T. paniculatum seedlings died out in $75 \%$ and $100 \%$ SMR substrates where higher electrical conductance was found (2.3-2.7 dS m $\left.\mathrm{m}^{-1}\right)$. Both growth and biomass mostly declined with the increase of SMR proportion in the growing media for the two species except for root biomass in T.paniculatum seedlings between the control and the 25\% SMR treatment. Shoot nitrogen (N) and phosphorus (P) concentrations and contents tended to be higher in low- and high-SMR-proportional substrates, respectively. $\mathrm{N}$ and $\mathrm{P}$ statuses were both diagnosed to be excessive than needed for the two species. Overall, it was not recommended to culture $G$. herbaceum seedlings in the substrates with SMR; instead T. paniculatum seedlings can be cultured in the growing media with SMR in volumetric proportion of $25 \%$.
\end{abstract}

Keywords: commercial weeds; medicinal plants; nutrient availability; nitrogen; phosphorus; spent mushroom residue

\section{Introduction}

Peat is an un-renewable resource that has been heavily exploited and made the natural reserve touch the warning-line. Intensive extraction of peat has led to the ecological degradation and stimulation of $\mathrm{CO}_{2}$ permission that contributes to the global warming (Bustamante et al., 2008). Russia and Finland accounted for over $40 \%$ of national peat production worldwide (Kalmari, 1991; Tcvetkov, 2017). Most of extracted peat are used for fuel industry and horticultural substrates. However, a limit has been foreseen for natural reserves if no alternative resource can be emerged.

Spent mushroom residue (SMR) is a by-product of mushroom production. Along with the establishment of huge mushroom industry, a considerable amount of SMR is being produced every year. Turkey, Spain, and China are producing the largest three amounts of SMRs as 0.2, 0.99, and 38.93 million tons, respectively. The increasing demand for mushroom production drives the increase of SMR accumulation, which has led to a new issue of solid waste heap. Piled SMRs can be used as the primary substance for extracting biofertilizers due to their abundant nutritive compounds that were derived from fungus (Elsakhawy and El-

Received: 19 Dec 2020. Received in revised form: 05 Feb 2021. Accepted: 10 Feb 2021. Published online: 22 Mar 2021.

From Volume 49, Issue 1, 2021, Notulae Botanicae Horti Agrobotanici Cluj-Napoca journal will use article numbers in place of the traditional method of continuous pagination through the volume. The journal will continue to appear quarterly, as before, with four annual numbers. 
Rahem, 2020). Another suggested way to reuse SMRs is the outlet as a substrate to amend soils (Li et al., 2020; Marin-Benito et al., 2020). The SMR compost was also suggested to be used as a growing-media that may partly replace peat for horticultural plant production (Caballero et al., 2009; Ribas et al., 2009).

As a possible replacement of peat, composted SMR has several merits, such as restricting pathogens (Chen et al., 2015; Segarra et al., 2007), promoting uptake (Paredes et al., 2016; Sönmez et al., 2016), and benefitting growth (Unal, 2015). As nutrient loss through leaching is an issue that should be considered in potted seedlings with peat (Zhu et al., 2016), no clear evidence has indicated any possible risk that was aroused by inputting SMR. However, the full replacement of peat by SMR compost has not been applicable due to high $\mathrm{pH}$ and electrical conductance (EC) (Szmidt and Chong, 1995; Gonani et al., 2011). With SMR addition, it

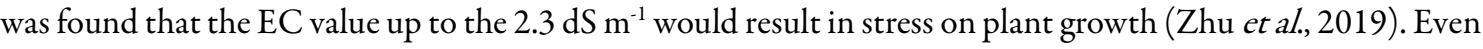
the deep compost cannot fully eliminate these negative impacts; hence only a small part of peats can be replaced by SMR in current growing media (Wei et al., 2020a; Wei et al., 2020b; Wei et al., 2020c). Zhu et al. (2019) put forward that SMR can be directly used as un-composted substrates under the condition of partly replacing peats in the growing media for cultivation of pepper (Capsicum annum L.) seedlings. The growing media with a quarter of fresh SMR was also successfully used for the cultivation of tree (Pinus koraiensis) (Wei et al., 2020a) and shrub (Aralia elata) (Wei et al., 2020b) plants that have commercial values. Tests are still scarce on herbaceous plants that are vulnerable to environment changes. Nutritional status of SMR-raised herbaceous plants is not clear in current literature.

Nutrient uptake and utilization are highly important for the culture of valued plants. Recently, the importance to test plant-nutritional budget has further been elevated in studies on horticultural plant culture with modern techniques (Zhao et al., 2017; Xu et al., 2019; Zhao et al., 2019; Zhu et al., 2019; Wei et al., 2020a; Wei et al., 2020b; Wei et al., 2020c; Zhao et al., 2020). They attract high concerns not only because of the relevance of nutrient budget (Zhao et al., 2019; Zhao et al., 2020), but also due to the indication of nutrient status that may forecast seedling quality (Xu et al., 2019). It has been documented that light spectra can modulate nutrient uptake and biomass accumulation (Wei et al., 2020a; Wei et al., 2020c) and biomass accumulation, which will further generate a combined effect to shape nutrient utilization (Zhao et al., 2019; Zhao et al., 2020). In this process, the meantime nutrient availability will cooperate to take part in the regulation of nutrient uptake, allocation, and utilization (Wei et al., 2020b). Both light and fertility have been demonstrated to have significant effect on the production of bioactive materials in horticultural plants (Wei et al., 2020c). Therefore, nutrient uptake and utilization are a synthesized matrix that can be the outcome of substrate property and the indication of by-product outcomes.

Gossypium herbaceum L. is a species of cotton with significant value in medicinal uses, such as women's menstrual cycle pains and irregular bleeding (Huang et al., 2020). Talinum paniculatum (Jacq.) Gaertn. 1971 is a highly valued plant that is used for traditional medicine due to anti-oxidative bioactive substances from extracts (Tolouei et al., 2019). Both species are found in natural habitats. Mushroom is widely produced in these regions and SMR has been but issue as solid piles. They are highly fragile at the early stage of artificial culture which arouses a challenge to use suitable growing media. In this study, fresh SMR was used as part of growing media mixed peat to culture $G$. herbaceum and T. paniculatum seedlings. It was hypothesized that: (i) the fresh SMR would not cause harmful impact on plants at the low proportion in the growing media; (ii) growth and nutrient uptake would be both maximized at the ratio of SMR involvement around a quarter in volume. According to Zhu et al. (2019), high proportion of SMR input may result in large range of mortality for pepper plants. We cannot assume this happen considering the difference between species attributes. However, we can accept the fact if unexpected mortality happened in our experiment. 


\section{Materials and Methods}

\section{Plant materials and growth condition}

Seeds of Gossypium herbaceum and Talinum paniculatum were sent to the Laboratory of Combined Manipulations of Illumination and Fertility on Plant Growth (Zhilunpudao Agric. S\&T Ltd., Changchun, China) $\left(43^{\circ} 58^{\prime} \mathrm{N}, 125^{\circ} 24^{\prime} \mathrm{E}\right)$ in Changchun city, Northeast China. Seeds were sterilized by soaking in $0.5 \%$ $(\mathrm{w} / \mathrm{w})$ potassium permanganate for $30 \mathrm{~min}$ and soaked in water at the room temperature for $12 \mathrm{~h}$. Seeds were sown in fine-ground peat which were moved to sowing trays and sealed with plastic fiber film. Seeds were germinating at the temperature of $24^{\circ} \mathrm{C}$ in the relative humidity of $90 \%$. Germinated embryos were transplanted to plants trays which have $32(4 \times 8)$ cavities $(13 \mathrm{~cm}$ depth and $7 \mathrm{~cm}$ top-diameter) that were filled with substrates of peat and SMR. Light was supplied by high pressure sodium lamps with the spectrum of $43.9 \%$ red $(600-700 \mathrm{~nm}), 54.7 \%$ green $(500-600 \mathrm{~nm})$, and $1.4 \%$ blue $(400-500 \mathrm{~nm})$ in a daily photoperiod of $16 \mathrm{~h}$. This illumination condition was successfully used for plant culture in previous studies (Wei et al., 2017; Zhao et al., 2017; An et al., 2018; Zhu et al., 2019). Seedlings were watered by sub-irrigation through placing trays in tanked water that were refilled every two days. This watering regime has been proven to enable the desired irrigation availability in the similar cultural system (Zhao et al., 2019; Wei et al., 2020a; Wei et al., 2020b). During the experiment, temperature was $16.8 / 31.7^{\circ} \mathrm{C}$ (night/day) and the relative humidity (RH) ranged between $49 \%$ and $94 \%$.

\section{Substrate treatment}

Substrates treatments varied by the proportion of SMR in growing-media as $0 \%$ (control), 25\%, 50\%, $75 \%$, and $100 \%(\mathrm{v} / \mathrm{v})$ with peat mixed together. The peat used in this study was adapted that from Zhu et al. (2019), which can solely be used as growing media for the culture most horticultural plants. Spent mushroom residue was obtained from a local mushroom factory in Changchun from the cultivation of Pleurotus eryngii. The raw materials to generate SMR included $20 \%$ cottonseed hull, $20 \%$ wood bits, $24 \%$ corncobs, $20 \%$ brans, $5 \%$ corn flour, $2 \%$ lime carbonate, $1 \%$ gypsum powder, and $8 \%$ bean pulp (Zhu et al., 2019). After the harvest of mushrooms, SMR was immediately moved out of plastic coating, crushed to pieces, and air-dried at indoor temperature until the weight was constant. A pile of peat was mixed by SMR and both were mixed to the aimed volumetric proportion. Mixed substrates were used to fill planting cavities in every tray. Filled trays received full watering and a second portion of substrate was added to the surface gap caused by wetted compression. Chemical properties of the five substrates are shown in Table 1. Each treatment was replicated for three times with one planting tray as a replicating unit.

Table 1. Chemical properties of the substrates with fresh spent mushroom substrate mixed with commercial peat in different proportions $(\mathrm{v} / \mathrm{v})$

\begin{tabular}{|c|c|c|c|c|c|}
\hline Treatment & $\mathrm{NH}_{4}^{+}-\mathrm{N}\left(\mathrm{mg} \mathrm{kg}^{-1}\right)$ & $\mathrm{NO}_{3}{ }^{-} \mathrm{N}\left(\mathrm{mg} \mathrm{kg}^{-1}\right)$ & $\mathrm{PO}_{4}^{3-}-\mathrm{P}\left(\mathrm{mg} \mathrm{kg}^{-1}\right)$ & $\mathrm{pH}$ & $\mathrm{EC}\left(\mathrm{dS} \mathrm{m}^{-1}\right)$ \\
\hline $0 \%$ & $124.74 \pm 4.92 \mathrm{a}$ & $152.51 \pm 8.63 \mathrm{a}$ & $232.29 \pm 18.26 \mathrm{e}$ & $4.29 \pm 0.05 \mathrm{~d}$ & $0.31 \pm 0.20 \mathrm{c}$ \\
\hline $25 \%$ & $121.75 \pm 2.02 \mathrm{a}$ & $137.63 \pm 3.56 \mathrm{a}$ & $364.88 \pm 3.45 \mathrm{~d}$ & $4.48 \pm 0.06 \mathrm{~cd}$ & $0.99 \pm 0.12 \mathrm{~b}$ \\
\hline $50 \%$ & $113.33 \pm 1.66 \mathrm{a}$ & $49.11 \pm 4.08 \mathrm{~b}$ & $510.52 \pm 8.78 \mathrm{c}$ & $4.66 \pm 0.05 \mathrm{c}$ & $1.54 \pm 0.23 \mathrm{~b}$ \\
\hline $75 \%$ & $74.35 \pm 10.79 \mathrm{~b}$ & $36.96 \pm 5.70 \mathrm{~b}$ & $637.86 \pm 10.43 \mathrm{~b}$ & $5.10 \pm 0.19 \mathrm{~b}$ & $2.35 \pm 0.29 \mathrm{a}$ \\
\hline $100 \%$ & $19.52 \pm 8.18 \mathrm{c}$ & $11.07 \pm 4.13 \mathrm{c}$ & $910.01 \pm 13.67 \mathrm{a}$ & $5.66 \pm 0.08 \mathrm{a}$ & $2.74 \pm 0.09 \mathrm{a}$ \\
\hline M.S. & 5976.84 & 12078.55 & 20423.17 & 0.94 & 2.94 \\
\hline$F_{\text {value }}$ & 124.79 & 353.14 & 1274.12 & 79.51 & 66.17 \\
\hline$P_{\mathrm{r}}>F$ & $<0.0001$ & $<0.0001$ & $<0.0001$ & $<0.0001$ & $<0.0001$ \\
\hline
\end{tabular}

Different letters in a column stand for significant difference among SMR treatments was tested by Tukey method at 0.05 level. 


\section{Plant culture, sampling, and chemical analysis}

Seedlings were cultured for four months until some trayed seedlings died out in the 100\% SMR treatment (Figure 1). Ten living seedlings were sampled from one planting tray and measured for their height and root-collar diameter (RCD). Height was measured as the length from root-collar scar to the tip of shoot. RCD was measured as the diameter of the stem $3 \mathrm{~cm}$ above the root-collar scar. Each sampled seedling was divided into shoot and root parts and both were dried in a ventilated oven at $70^{\circ} \mathrm{C}$ for $72 \mathrm{~h}$. Dried samples were ground and determined for nitrogen $(\mathrm{N})$ and phosphorus $(\mathrm{P})$ concentrations. A sample in the weight of about $0.2 \mathrm{~g}$ was digested in $5 \mathrm{~mL}$ mixture of hydrogen peroxide and sulfuric acid. The digested solution was diluted to $50 \mathrm{~mL}$. Total N concentration was determined Kjeldahl method (Salifu and Timmer, 2003). Total P concentration was determined by the Molybdenum-anticolorimetry method (Zhao et al., 2020).
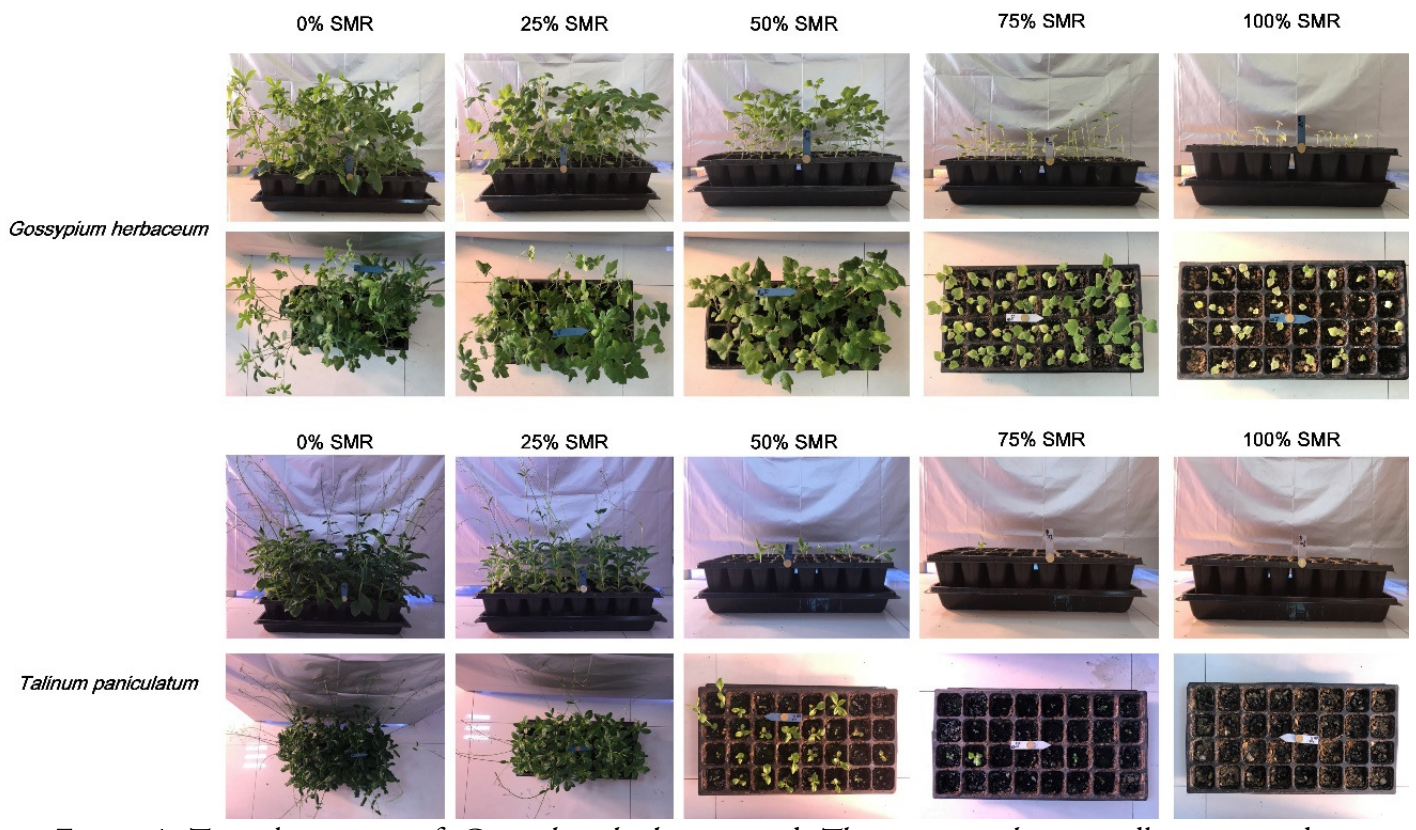

Figure 1. Typical outcome of Gossyplum herbaceum and Tlinum paniculatum seedlings exposed to growing media with peat and spent mushroom residue (SMR) in proportions of $0,25 \%, 50 \%, 75 \%$, and $100 \%$

\section{Statistical analysis}

Statistical analysis was made by SPSS software (IBM, New York, U.S.A.). All data were tested for their normal distribution and no data transformation was necessary. Data were analysed by a two-way analysis of variance (ANOVA) with two species (G. herbaceum and T. paniculatum) and five treatments $(0 \%, 25 \%, 50 \%$, $75 \%, 100 \%$ proportion of SMR in the growing media) as fixed factors. Because T. paniculatum seedlings died out in $100 \%$ SMR treatment and the number of survived ones in the $75 \%$ SMR treatment was fewer than 10 , data were analysed by a factorial analysis of $2 \times 3$ factors arrangement with two species in $0 \%, 25 \%$, and $50 \%$ SMR treatments. When significant effect was indicated by ANOVA $(\alpha=0.05)$, data in response to the six combined treatments were compared by a one-way ANOVA plus two other treatments of $75 \%$ and $100 \%$ SMR on $G$. herbaceum seedlings. This analysis of combined treatments with hanging-up new comers was also used in the study on soil amendment (Wei et al., 2012). The significant difference in comparison was tested by Tukey method at 0.05 level. Vector diagnosis was used to evaluate nutritional status for $\mathrm{N}$ and $\mathrm{P}$ according to the methodology by Salifu and Timmer (2003). This technique has been widely used for the diagnosis of nutrient status in plants subjected to light and substrate combination (Li et al., 2018; Wei et al., 2020a; Wei et al., 2020b). 


\section{Results}

\section{Responsive performance}

Seedlings of $G$. herbaceum generally showed better responses of survival and growth to SMR substrates than those of T. paniculatum (Figure 1). Shoots of G. herbaceum seedlings subjected to the $100 \%$ SMR treatment failed to initiate the second flush and showed yellow leaves in most surviving individuals. Survival of G. herbaceum seedlings in the $75 \%$ SMR treatment was higher but parts of individuals had yellow leaves. Seedlings of T. paniculatum died out in the $100 \%$ SMR treatment and most individuals died in the $75 \%$ SMR treatment. Although over half of T. paniculatum seedlings survived in the 50\% SMR treatment, leaves of living individuals did not look green as expected.

\section{Shoot growth}

Factors of species and SMR treatment had an interactive effect on height growth and RCD (Table 2). Talinum paniculatum seedlings showed highest plant height in the control $\left(F_{7,16}=49.37 ; P<0.0001\right)$ (Figure 2A). Root-collar diameter of $G$. herbaceum seedlings in the control was also as high as that of $T$. paniculatum $\left(F_{7,16}=98.40 ; P<0.0001\right)$ (Figure $\left.2 \mathrm{~B}\right)$. Both height and RCD generally showed a decreasing trend with the increase of SMR ratio in the growing media. Both height and RCD were lower in the 50\% SMR treatment than those in the control in T. paniculatum seedlings. Height and RCD were lower in the $75 \%$ and $100 \%$ SMR treatments than those in the control in G. herbaceum seedlings.

Table 2. $F$ and $P$ values from analysis of variance (ANOVA) of species, spent-mushroom residue ratio

(SMR), and their interaction on seedling growth, biomass and nutrient uptake

\begin{tabular}{|c|c|c|c|c|}
\hline Parameters & ANOVA & Species & SMR & Species $\times$ SMR \\
\hline \multirow{2}{*}{ Seedling height } & $F$ value & $11.04^{1}$ & 70.91 & 18.19 \\
\hline & $P$ value & 0.0061 & $<0.0001$ & 0.0002 \\
\hline \multirow{2}{*}{$\mathrm{RCD}^{2}$} & $F$ value & 6.39 & 234.18 & 11.83 \\
\hline & $P$ value & 0.0265 & $<0.0001$ & 0.0015 \\
\hline \multirow{2}{*}{ Shoot biomass } & $F_{\text {value }}$ & 1.21 & 197.69 & 13.26 \\
\hline & $P$ value & 0.2921 & $<0.0001$ & 0.0009 \\
\hline \multirow{2}{*}{ Root biomass } & $F$ value & 58.58 & 86.14 & 48.83 \\
\hline & $P$ value & $<0.0001$ & $<0.0001$ & $<0.0001$ \\
\hline \multirow{2}{*}{$\mathrm{RS}^{3}$} & $F$ value & 35.58 & 100.13 & 84.68 \\
\hline & $P$ value & $<0.0001$ & $<0.0001$ & $<0.0001$ \\
\hline \multirow{2}{*}{ Shoot $\mathrm{N}^{4}$ concentration } & $F$ value & 2.58 & 1.29 & 7.45 \\
\hline & $P$ value & 0.1344 & 0.3100 & 0.0079 \\
\hline \multirow{2}{*}{ Root $\mathrm{N}$ concentration } & $F$ value & 78.14 & 2.57 & 34.45 \\
\hline & $P$ value & $<0.0001$ & 0.1180 & $<0.0001$ \\
\hline \multirow{2}{*}{ Shoot $\mathrm{P}^{5}$ concentration } & $F$ value & 209.68 & 34.13 & 25.38 \\
\hline & $P$ value & $<0.0001$ & $<0.0001$ & $<0.0001$ \\
\hline \multirow{2}{*}{ Root $\mathrm{P}$ concentration } & $F$ value & 147.91 & 392.38 & 284.67 \\
\hline & $P$ value & $<0.0001$ & $<0.0001$ & $<0.0001$ \\
\hline \multirow{2}{*}{ Shoot $\mathrm{N}$ content } & $F_{\text {value }}$ & 14.09 & 289.24 & 66.71 \\
\hline & $P$ value & 0.0028 & $<0.0001$ & $<0.0001$ \\
\hline \multirow{2}{*}{ Root $N$ content } & $F$ value & 6.66 & 79.44 & 49.10 \\
\hline & $P$ value & 0.0241 & $<0.0001$ & $<0.0001$ \\
\hline \multirow{2}{*}{ Shoot $\mathrm{P}$ content } & $F_{\text {value }}$ & 58.29 & 413.00 & 84.80 \\
\hline & $P$ value & $<0.0001$ & $<0.0001$ & $<0.0001$ \\
\hline \multirow{2}{*}{ Root $\mathrm{P}$ content } & $F_{\text {value }}$ & 43.75 & 82.08 & 43.57 \\
\hline & $P$ value & $<0.0001$ & $<0.0001$ & $<0.0001$ \\
\hline
\end{tabular}

Note: ${ }^{1}$ value in bold font indicate significant effect; ${ }^{2} \mathrm{RCD}$, root-collar diameter; ${ }^{3} \mathrm{RS}$, root to shoot biomass ratio; ${ }^{4}$ $\mathrm{N}$, nitrogen; ${ }^{5} \mathrm{P}$, phosphorus. 

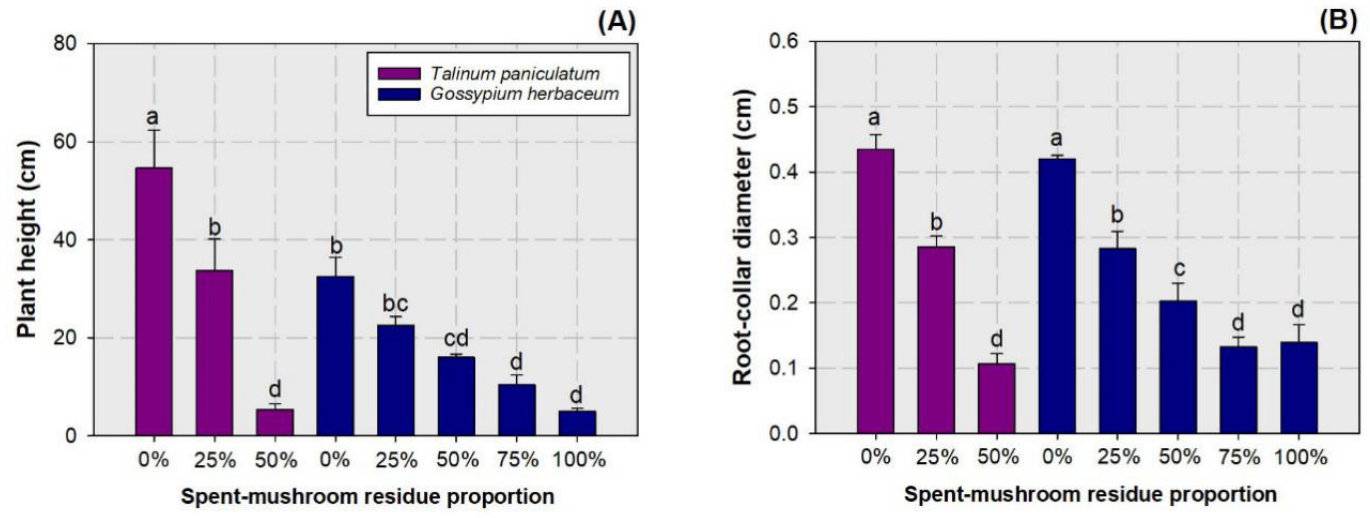

Figure 2. Plant height (A) and root-collar diameter (B) in Gossyplum herbaceum and Tlinum paniculatum seedlings exposed to growing media with peat and spent mushroom residue (SMR) in proportions of $0 \%$, $25 \%, 50 \%, 75 \%$, and $100 \%$ for $G$. herbaceum and $0 \%, 25 \%$, and $50 \%$ for T. Paniculatum

Error bars label standard errors. Different letters indicate significant difference at 0.05 level according to the Tukey test.

\section{Biomass accumulation and allocation}

Factors of species and SMR treatment had an interactive effect on biomass accumulation in shoot and root and allocation between root and shoot (Table 2). Shoot biomass was lower in SMR treatments from 25\% up to $100 \%$ compared to the control for both species $\left(F_{7,16}=18.98 ; P<0.0001\right)$ (Figure 3A). In $G$. herbaceum seedlings, shoot biomass was also lower in the $75 \%$ and $100 \%$ SMR treatments relative to the control. In $T$. paniculatum seedlings, root biomass in the $25 \%$ SMR treatment was not statistically different from that in the control. Root biomass was lower in the $75 \%$ and $100 \%$ SMR treatments compared to the control for $G$. herbaceum seedlings $\left(F_{7,16}=77.88 ; P<0.0001\right)$ (Figure $\left.3 \mathrm{~A}\right)$.
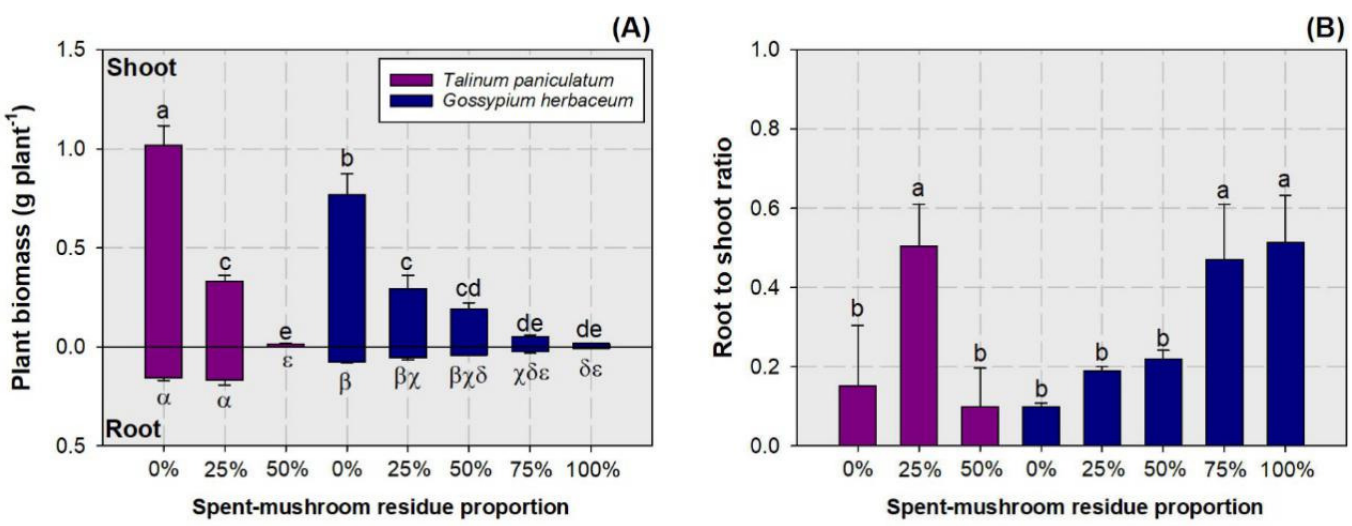

Figure 3. Plant biomass accumulation (A) and root to shoot biomass ratio (B) in Gossyplum herbaceum and Tlinum paniculatum seedlings exposed to growing media with peat and spent mushroom residue (SMR) in proportions of $0 \%, 25 \%, 50 \%, 75 \%$, and $100 \%$ for $G$. herbaceum and $0 \%, 25 \%$, and $50 \%$ for $T$. Paniculatum

Error bars label standard errors. Different letters indicate significant difference at 0.05 level according to the Tukey test. Lower case letters label difference for shoot and roman letters for root. 
Factors of species and SMR treatment had an interactive effect on root to shoot biomass ratio $(\mathrm{R} / \mathrm{S})$ (Table 2). In T. paniculatum seedlings, $\mathrm{R} / \mathrm{S}$ was higher in the $25 \% \mathrm{SMR}$ treatment than that in the control and in the 50\% SMR treatment $\left(F_{7,16}=18.98 ; P<0.0001\right)$ (Figure 3B). The $\mathrm{R} / \mathrm{S}$ tended to rise with the increase of SMR proportion in the substrates. The R/S was higher in the $75 \%$ and $100 \%$ SMR treatments than that in the control.

\section{Nitrogen and phosphorus concentrations}

Factors of species and SMR treatment had an interactive effect on $\mathrm{N}$ and $\mathrm{P}$ concentrations in shoot and root parts in both species (Table 2). Nitrogen concentration declined with the increase of SMR proportion in growing media in $T$. paniculatum shoots $\left(F_{7,16}=5.70 ; P=0.0019\right)$ (Figure $\left.4 \mathrm{~A}\right)$. Shoot $\mathrm{N}$ concentration was not different in the SMR treatments from that in the control. Root $\mathrm{N}$ concentration was highest in controlled $G$. herbaceum seedlings followed by that in same species of seedlings subjected to the $25 \%$ and $50 \%$ SMR treatments $\left(F_{7,16}=38.71 ; P<0.0001\right)$ (Figure $\left.4 \mathrm{~B}\right)$. Root $\mathrm{N}$ concentration was higher in the $25 \%$ and $50 \% \mathrm{SMR}$ treatments compared to the control for T. paniculatum seedlings. Controlled T. paniculatum seedlings and $G$. herbaceum seedlings in the $75 \%$ SMR treatment had the lowest root $\mathrm{N}$ concentration. Whole-plant $\mathrm{N}$ concentration was highest in controlled T. paniculatum seedlings and $G$. herbaceum seedlings exposed to the $25 \%$ and $50 \%$ SMR treatments $\left(F_{7,16}=5.53 ; P=0.0022\right)$ (Figure $\left.4 \mathrm{C}\right)$. Talinum paniculatum seedlings in the 50\% SMR treatment and G. herbaceum seedlings in the 75\% SMR treatment had the lowest whole-plant N concentration.
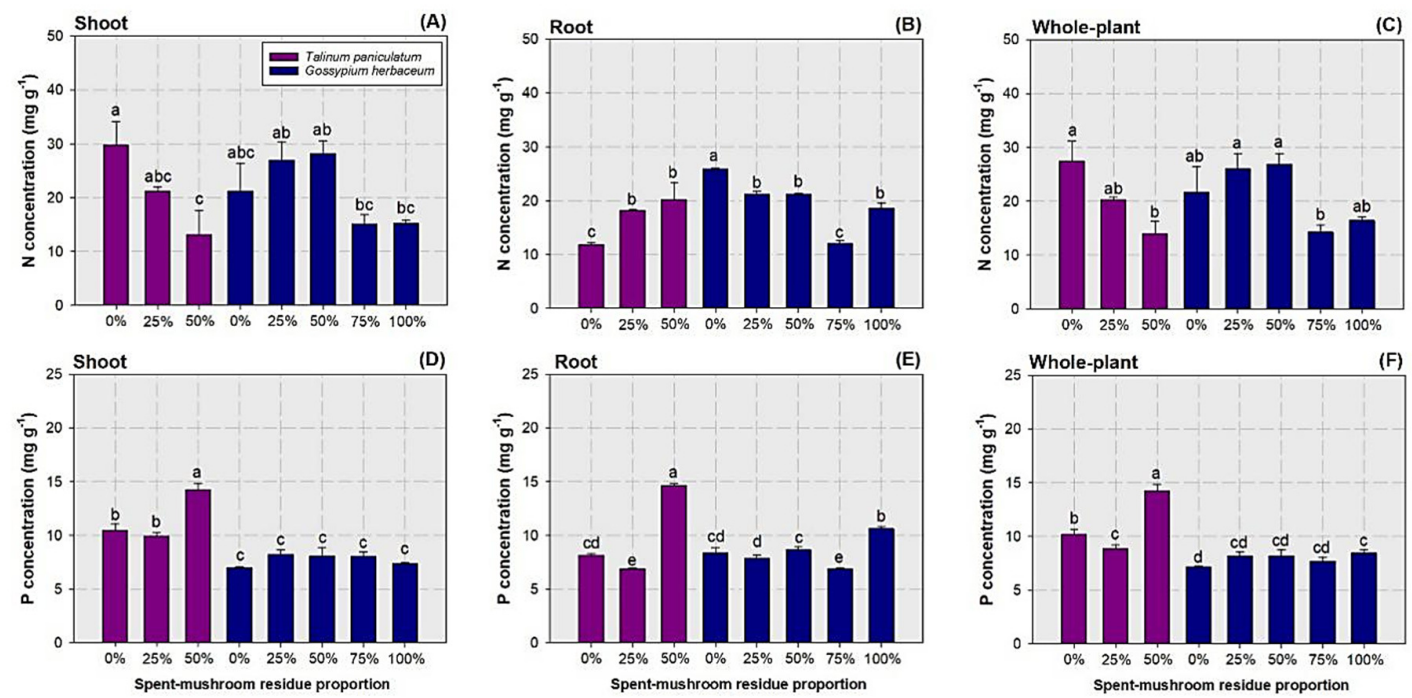

Figure 4. Concentrations of nitrogen $(\mathrm{N})$ (top) and phosphorus (P) (bottom) in shoot (left), root (middle), and whole-plant (right) in Gossyplum herbaceum and Tlinum paniculatum seedlings exposed to growing media with peat and spent mushroom residue (SMR) in proportions $0 \%, 25 \%, 50 \%, 75 \%$, and $100 \%$ for $G$. herbaceum and $0 \%, 25 \%$, and $50 \%$ for T. Paniculatum

Error bars label standard errors. Different letters indicate significant difference at 0.05 level according to the Tukey test.

Shoot $\mathrm{P}$ concentration was highest in T. paniculatum seedlings subjected to the $50 \%$ SMR treatment, followed by that in the same species of seedlings subjected to the control and the $25 \%$ SMR treatment $\left(F_{7,16}=65.99 ; P<0.0001\right)$ (Figure 4D). Shoot $P$ concentration in $G$. herbaceum seedlings was lower than that in T. paniculatum seedlings without significant difference among SMR treatments. Root P concentration was also highest in $T$. paniculatum seedlings subjected to the 50\% SMR treatment and that in G. herbaceum seedlings subjected to the $100 \% \mathrm{SMR}$ treatment was the second highest $\left(F_{7,16}=297.14 ; P<0.0001\right)$ (Figure $\left.4 \mathrm{E}\right)$. 
Root $\mathrm{P}$ concentration in $T$. paniculatum seedlings subjected to the $25 \%$ SMR treatment and that in $G$. herbaceum seedlings subjected to the $75 \%$ SMR treatment showed the lowest level. Whole-plant P concentration was highest in T. paniculatum seedlings subjected to the 50\% SMR treatment and lowest in $G$. herbaceum seedlings subjected to the control (Figure 4F).

\section{Nitrogen and phosphorus contents}

Factors of species and SMR treatment had an interactive effect on $\mathrm{N}$ and $\mathrm{P}$ contents in shoot and root parts in both species (Table 2). Shoot $\mathrm{N}$ content declined with the increase of SMR proportion in the growing media for both species $\left(F_{7,16}=178.78 ; P<0.0001\right)$ (Figure $\left.5 \mathrm{~A}\right)$. However, root $\mathrm{N}$ content was highest in $T$. paniculatum seedlings subjected to the $25 \%$ SMR treatment, followed by that in controlled $T$. paniculatum seedlings and $G$. herbaceum seedlings $\left(F_{7,16}=70.05 ; P<0.0001\right)$.
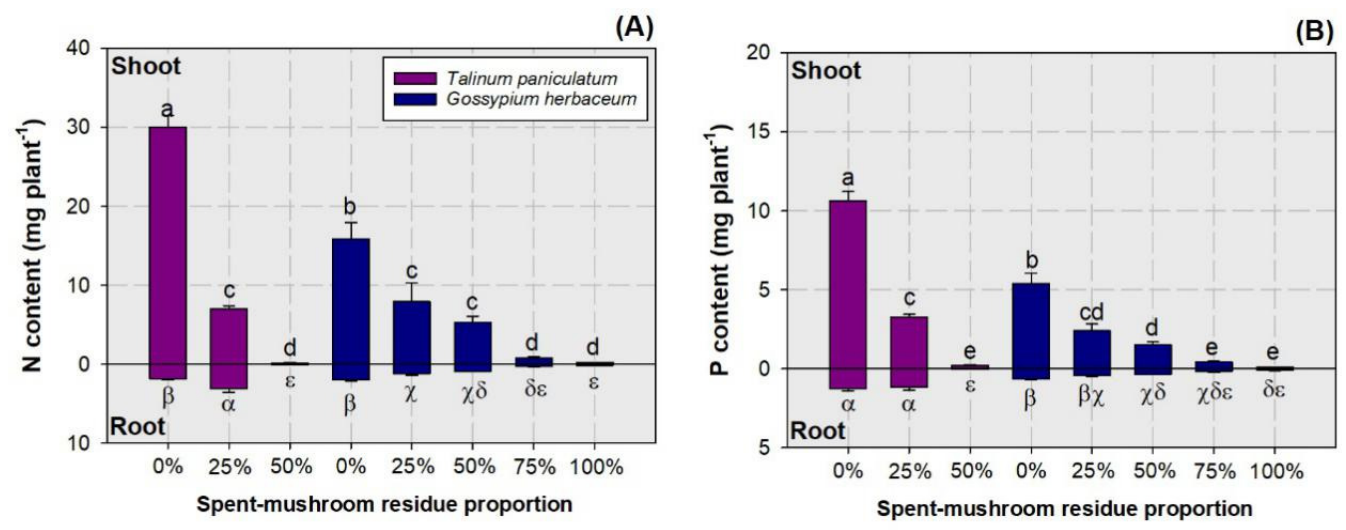

Figure 5. Contents of N (A) and P (B) in shoot and root parts of Gossyplum herbaceum and Tlinum paniculatum seedlings exposed to growing media with peat and spent mushroom residue (SMR) in proportions of $0 \%, 25 \%, 50 \%, 75 \%$, and $100 \%$ for G. herbaceum and $0 \%, 25 \%$, and $50 \%$ for T. Paniculatum Error bars label standard errors. Different letters indicate significant difference at 0.05 level according to the Tukey test. Lower case letters label difference for shoot and roman letters for root.

Shoot $\mathrm{P}$ content also declined with the increase of $S M R$ proportion in the growing media $\left(F_{7,16}=257.22\right.$; $P<0.0001)$ (Figure 5B). Root $\mathrm{P}$ content was highest in $T$. paniculatum seedlings subjected to the control and the $25 \%$ SMR treatment $\left(F_{7,16}=72.18 ; P<0.0001\right)$. Root $P$ content declined with the increase of SMR proportion in the growing media.

\section{Diagnosis of nitrogen and phosphorus statuses}

Compared to the control, SMR treatments resulted in the symptom of nutrient excess for both species, but the cause of nutrient excess was various (Figure 6). In T. paniculatum seedlings, both proportions of $25 \%$ and $50 \%$ SMR in the growing media resulted in antagonistic $\mathrm{N}$ excess because of multiple declines in biomass, $\mathrm{N}$ content and concentration (Figure 6A). In T. paniculatum seedlings, the lower SMR proportion of $25 \%$ also resulted in antagonistic $\mathrm{P}$ excess, but the higher proportion of $50 \%$ led to toxic $\mathrm{P}$ accumulation due to the increase of P concentration relative to the control (Figure 6B). In G. herbaceum seedlings, lower SMR proportions of $25 \%$ and $50 \%$ resulted in the toxic $\mathrm{N}$ accumulation but higher proportions of $75 \%$ and $100 \%$ resulted in antagonistic $\mathrm{N}$ excess (Figure 6C). The $\mathrm{P}$ status was indicated to be toxic accumulation in $G$. herbaceum seedlings subjected to all SMR treatments (Figure 6D). 

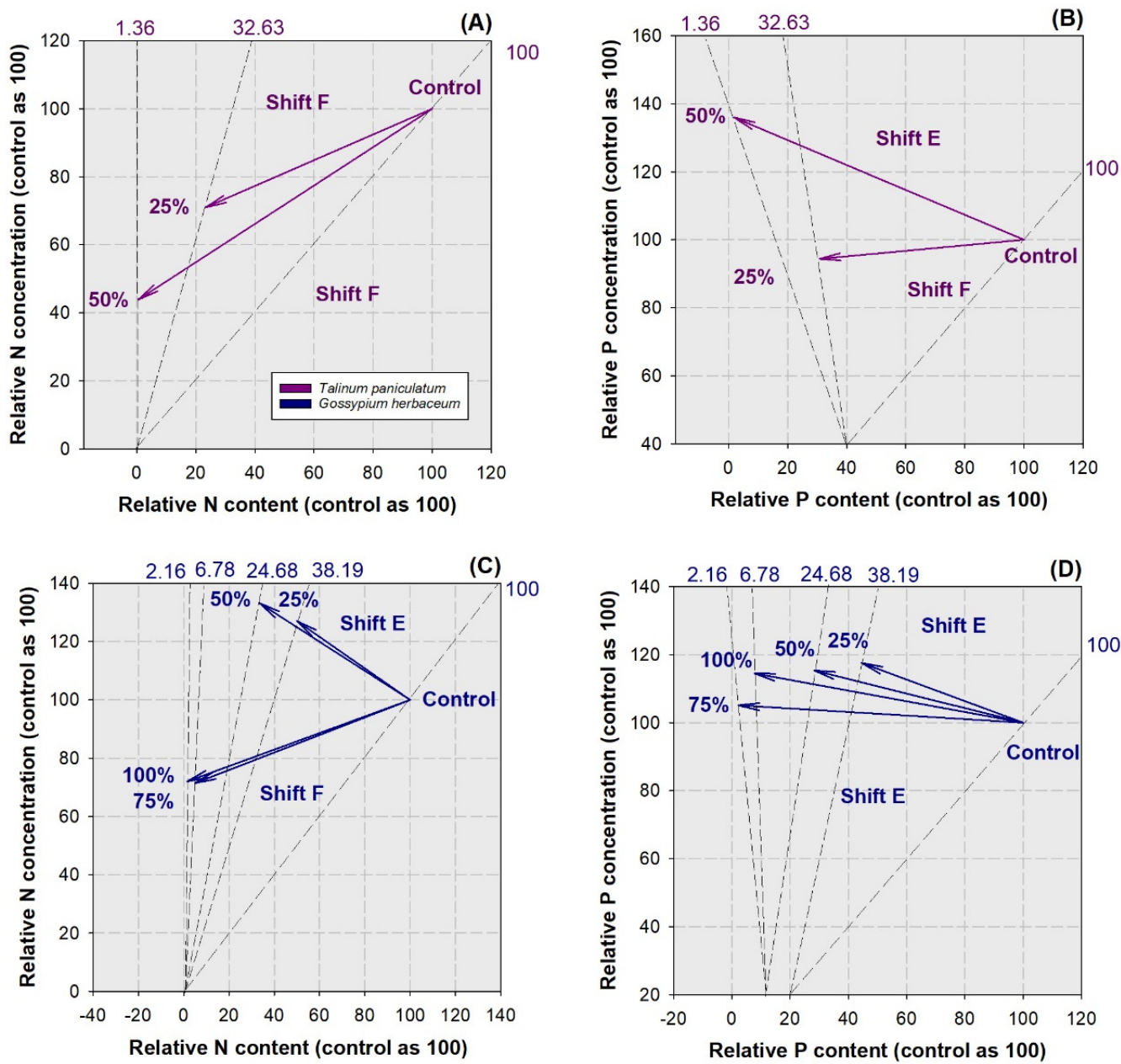

Figure 6. Vector diagnosis of $\mathrm{N}$ and $\mathrm{P}$ statuses in shoots of Gossyplum herbaceum and Tlinum paniculatum seedlings exposed to growing media with peat and spent mushroom residue (SMR) in proportions of $0,25 \%, 50 \%, 75 \%$, and $100 \%$

Shifts interpretations are adapted from Salifu and Timmer (2003). Shift E stands for nutrient excess caused by toxic accumulation. Shift $\mathrm{F}$ stands for antagonistic excess.

\section{Discussion}

As we indicated, the high proportion (over 50\%) of SMR in the growing media generated negative impacts on plant growth of the two species. This negative influence had a species-specific response that $G$. herbaceum seedlings can endure SMR at a high proportion with weakened growth, but $T$. paniculatum seedlings cannot endure SMR at the proportion from $75 \%$ to 100\%. High EC in SMR-enriched growing media was caused by high levels of ions and salts (Medina et al., 2009). According to the negative response of $T$. paniculatum seedlings to the high-proportion SMR substrates, this species is more sensitive to salt stress; hence occurred higher mortality than in $G$. herbaceum seedlings. Distinctly negative attributes to high salt stress also occurred on other plant species. Medina et al. (2009) reported that tomato plants are less sensitive to salt than pepper and courgette when cultured with the growing media with SMR. Therein, only tomato plants out of all species tested can endure high proportion of SMR.

Both species showed a decrease in shoot growth in response to the increase of SMR in the growth media. Controlled seedlings without any SMR addition showed the best responses in growth and biomass 
accumulation. These results suggest that the two economical plants we used were unsuitable to be cultured by the growing media with SMR. Nevertheless, results from Zhu et al. (2019) did not concur with ours because $25 \%$-SMR increased shoot growth in pepper seedlings. Root biomass in our plants was not changed in 25\%SMR as it was for shoot biomass. More biomass was allocated to roots in high proportions of SMR for $G$. herbaceum but in the low proportion (no higher than 25\%) for T. paniculatum. In accordance with our findings, pepper plants were also found to have more biomass allocated to roots by more SMR used in the growing media (Zhu et al., 2019). Therefore, biomass allocation to roots functioned as a mechanism to account for the difference of sensitivities of the two plant species to the proportion of SMR. The ability to make biomass translocation to roots explained at least parts of the reason that $G$. herbaceum can survive when facing high SMR proportion.

Regarding the species-specific response to the mixture with SMR, we cannot accept our first hypothesis even at low proportion. However, if the promotion of shoot growths was not the main object in the cultural system, the growing media with $25 \%$ SMR and $75 \%$ peat can be used, but not recommended, for the two species. The only merit of $25 \%$-SMR substrates for dry mass production can be confirmed through our results was that high biomass-allocation to roots benefits the under-ground biomass pool in $T$. paniculatum if being cultured as a traditional source of medicine.

The high $\mathrm{N}$ concentration in shoots was driven by high $\mathrm{NH}_{4}{ }^{+}-\mathrm{N}$ and $\mathrm{NO}_{3}-\mathrm{N}$ concentrations in the substrates with low SMR proportions. In contrast, higher proportion of SMR increased the concentration of available $P$. Hence, seedlings tended to have higher $P$ concentration in substrates with higher SMR proportions. These results about $\mathrm{P}$ budget concur with those of $\mathrm{P}$ uptake and utilization in horticultural plants (Medina et al., 2009; Zhu et al., 2019). Because of the decline of biomass with the increase of SMR in the growing media, $\mathrm{N}$ and $\mathrm{P}$ contents also showed a decreasing trend along the gradient of SMR proportion from low to high. After all, both species in our study showed excessive symptoms of $\mathrm{N}$ and $\mathrm{P}$ to any proportional addition of SMR to the growing media. This was mainly caused by the decline of biomass in SMR-amended substrates. Therefore, we cannot accept our second hypothesis, but we concur with our preceding findings that the two species are not suitable to be cultured by the growing media.

\section{Conclusions}

Although we conducted this study on Talinum paniculatum and Gossypim herbaceum seedlings with empirical manipulations according to existed experiments, our results do not concur with most of findings in the horticultural plants. Talinum paniculatum is not suitable to be cultured by the growing media with SMR mainly due to depressed growth, decreased biomass accumulation, and subsequently nutrient excess. However, it can be suggested to culture $T$. paniculatum seedlings with growing media of $25 \%$ SMR regarding more biomass allocated to root as an invest of source to commercial organ in this species. Our results can be a set of theoretical references for the environmental advice to eliminate the possible contamination of solid water accumulation. Our findings about biomass production and allocation can also be used as the evidence for the culture of medicinal plants if dry mass production was set as the aim to enlarge the reserve for medical components.

\section{Authors' Contributions}

Conceptualization: HZ and YL; Data curation: HZ and AJ; Formal analysis: JT and YL; Funding acquisition: YL and HZ; Investigation: SZ and AJ; Methodology: YL; Project administration: YL; Resources: YL; Software: AJ and JT; Supervision: YL; Validation: HZ and SZ; Visualization: HZ; Writing - original draft: HZ; Writing - review and editing: YL. All authors read and approved the final manuscript. 


\section{Acknowledgements}

This work was supported by Jilin Province Science and Technology Development Project, grant number $20190304014 Y$; and funded by PhD Start-up Fund of Jilin Agricultural University 202020791.

\section{Conflict of Interests}

The authors declare that there are no conflicts of interest related to this article.

\section{References}

Bustamante MA, Paredes C, Moral R, Agullo E, Perez-Murcia MD, Abad M (2008). Composts from distillery wastes as peat substitutes for transplant production. Resources Conservation and Recycling 52(5):792-799. https://doi.org/10.1016/j.resconrec.2007.11.005

Caballero R, Pajuelo P, Ordovas J, Carmona E, Delgado A (2009). Evaluation and correction of nutrient availability to Gerbera jamesonii H. Bolus in various compost-based growing media. Scientia Horticulturae 122(2):244-250. https://doi.org/10.1016/j.scienta.2009.05.010

Chen JT, Lin MJ, Huang JW (2015). Efficacy of spent blewit mushroom compost and Bacillus aryabhattai combination on control of Pythium damping-off in cucumber. Journal of Agricultural Science 153(7):1257-1266. https://doi.org/10.1017/s0021859614000987

Elsakhawy TA, El-Rahem WTA (2020). Evaluation of spent mushroom substrate extract as a biofertilizer for growth improvement of rice (Oryza sativa L). Egyptian Journal of Soil Science 60(1):31-42. https://doi.org/10.21608/ejss.2019.18835.1320

Gonani Z, Riahi H, Sharifi K (2011). Impact of using leached spent mushroom compost as a partial growing media for horticultural plants. Journal of Plant Nutrition 34(3):337-344. https://doi.org/10.1080/01904167.2011.536876

Huang G, Wu ZG, Percy RG, Bai MZ, Li Y, Frelichowski JE, ... Zhu YX (2020). Genome sequence of Gossypium herbaceum and genome updates of Gossypium arboreum and Gossypium hirsutum provide insights into cotton A-genome evolution. Nature Genetics 52(5):516-+. https://doi.org/10.1038/s41588-020-0607-4

Kalmari A (1991). Finnish peat - Important bioenergy option and Finnish peat technology applications in the USA. Energy Sources 13(1):77-85. https://doi.org/10.1080/00908319108908970

Li FL, Kong QB, Zhang Q, Wang HP, Wang LM, Luo T (2020). Spent mushroom substrates affect soil humus composition, microbial biomass and functional diversity in paddy fields. Applied Soil Ecology 149:4. https://doi.org/10.1016/j.apsoil.2019.103489

Li XW, Chen QX, Lei HQ, Wang JW, Yang S, Wei HX (2018). Nutrient uptake and utilization by fragrant rosewood (Dalbergia odorifera) Seedlings cultured with oligosaccharide addition under different lighting spectra. Forests 9(1):15. https://doi.org/10.3390/f9010029

Marin-Benito JM, Carpio MJ, Mamy L, Andrades MS, Sanchez-Martin MJ, Rodriguez-Cruz MS (2020). Field measurement and modelling of chlorotoluron and flufenacet persistence in unamended and amended soils. Science of the Total Environment 725:8. https://doi.org/10.1016/j.scitotenv.2020.138374

Medina E, Paredes C, Perez-Murcia MD, Bustamante MA, Moral R (2009). Spent mushroom substrates as component of growing media for germination and growth of horticultural plants. Bioresource Technology 100(18):42274232. https://doi.org/10.1016/j.biortech.2009.03.055

Paredes C, Medina E, Bustamante MA, Moral R (2016). Effects of spent mushroom substrates and inorganic fertilizer on the characteristics of a calcareous clayey-loam soil and lettuce production. Soil Use and Management 32(4):487494. https://doi.org/10.1111/sum.12304

Ribas LCC, de Mendonca MM, Camelini CM, Soares CHL (2009). Use of spent mushroom substrates from Agaricus subrufescens (syn. A. blazei, A. brasiliensis) and Lentinula edodes productions in the enrichment of a soil-based potting media for lettuce (Lactuca sativa) cultivation: Growth promotion and soil bioremediation. Bioresource Technology 100(20):4750-4757. https://doi.org/10.1016/j.biortech.2008.10.059 
Salifu KF, Timmer VR (2003). Optimizing nitrogen loading of Picea mariana seedlings during nursery culture. Canadian Journal of Forest Research-Revue Canadienne De Recherche Forestiere 33(7):1287-1294. https://doi.org/10.1139/x03-057

Segarra G, Casanova E, Borrero C, Aviles M, Trillas I (2007). The suppressive effects of composts used as growth media against Botrytis cinerea in cucumber plants. European Journal of Plant Pathology 117(4):393-402. https://doi.org/10.1007/s10658-007-9108-X

Sönmez I, Kalkan H, Demir H (2016). Effects of spent mushroom compost on seedling quality and nutrient contents of eggplants (Solanum melongena) grown in different growing media. Acta Horticulturae 1142:403-408. https://doi.org/10.17660/ActaHortic.2016.1142.61

Szmidt RAK, Chong C (1995). Uniformity of spent mushroom substrate (SMS) and factors in applying recommendations for use. Compost Science \& Utilization 3(1):64-71. https://doi.org/10.1080/1065657x.1995.10701770

Tcvetkov PS (2017). The history, present status and future prospects of the Russian fuel peat industry. Mires and Peat 19:12. https://doi.org/10.19189/MaP.2016.OMB.256

Tolouei SEL, Palozi RAC, Tirloni CAS, Marques AAM, Schaedler MI, Guarnier LP, ... Gasparotto A (2019). Ethnopharmacological approaches to Talinum paniculatum (Jacq.) Gaertn. - Exploring cardiorenal effects from the Brazilian Cerrado. Journal of Ethnopharmacology 238:12. https://doi.org/10.1016/j.jep.2019.111873

Unal M (2015). The utilization of spent mushroom compost applied at different rates in tomato (Lycopersicon esculentum Mill.) seedling production. Emirates Journal of Food and Agriculture 27(9):692-697. https://doi.org/10.9755/ejfa.2015-05-206

Wei H, Zhao H, Chen X, He X (2020c). Secondary metabolites, carbohydrate accumulation, and nutrient uptake in Aralia elata (Miq.) Seem seedlings exposed to shoot cutting and different LED spectra. Acta Physiologiae Plantarum 42(11)https://doi.org/10.1007/s11738-020-03149-2

Wei HX, Chen GS, Chen X, Zhao HT (2020b). Growth and nutrient uptake in Aralia elata seedlings exposed to exponential fertilization under different illumination spectra. International Journal of Agriculture and Biology 23(3):644-652. https://doi.org/10.17957/ijab/15.1336

Wei HX, Guo P, Zheng HF, He XY, Wang PJ, Ren ZB, Zhai C (2017). Micro-scale heterogeneity in urban forest soils affects fine root foraging by ornamental seedlings of Buddhist pine and Northeast yew. Urban Forestry \& Urban Greening 28:63-72. https://doi.org/10.1016/j.ufug.2017.10.006

Wei HX, Hauer RJ, Chen GS, Chen X, He XY (2020a). Growth, nutrient assimilation, and carbohydrate metabolism in Korean pine (Pinus koraiensis) seedlings in response to light spectra. Forests 11(1):18. https://doi.org/10.3390/f11010044

Wei HX, Xu CY, Hawkins BJ, Ma LY, Jiang LN (2012). Organic amendment and inorganic fertilization affect soil properties and quality of Larix olgensis bareroot stock. New Forests 43(2):155-168. https://doi.org/10.1007/s11056-011-9270-z

Xu L, Zhang X, Zhang DH, Wei HX, Guo J (2019). Using morphological attributes for the fast assessment of nutritional responses of Buddhist pine (Podocarpus macrophyllus Thunb. D. Don) seedlings to exponential fertilization. Plos One 14(12):14. https://doi.org/10.1371/journal.pone.0225708

Zhao J, Chen X, Wei HX, Lv J, Chen C, Liu XY, .. Jia LM (2019). Nutrient uptake and utilization in Prince Rupprecht's larch (Larix principis-rupprechtii Mayr.) seedlings exposed to a combination of light-emitting diode spectra and exponential fertilization. Soil Science and Plant Nutrition 65(4):358-368. https://doi.org/10.1080/00380768.2019.1631715

Zhao Y, Wang Z, Wei HX, Bao YJ, Gu P (2017). Effect of prolonged photoperiod on morphology, biomass accumulation and nutrient utilization in post transplant Taxus cuspidata seedlings. Pakistan Journal of Botany 49(4):1285-1290. https://doi.org/pakbs.org/pjbot

Zhao Y, Wang Z, Xu S, Li Y, He C (2020). Nutrient assimilation and utilization in korean pine (Pinus koraiensis) seedlings exposed to exponential fertilization under contrasting spectra. Communications in Soil Science and Plant Analysis 51(18):2414-2428. https://doi.org/10.1080/00103624.2020.1836210

Zhu H, Zhao SJ, Yang JM, Meng LQ, Luo YQ, ... Liu WC (2019). Growth, nutrient uptake, and foliar gas exchange in pepper cultured with un-composted fresh spent mushroom residue. Notulae Botanicae Horti Agrobotanici ClujNapoca 47(1):227-236. https://doi.org/10.15835/nbha47111307 
Zhu K, Liu H, Wei H, Zhou J, Zou Q, Ma G, Zhang J (2016). Prediction of nutrient leaching from culture of containerized Buddhist pine and Japanese maple seedlings exposed to extended photoperiod. International Journal of Agriculture and Biology 18(2):425-434. https://doi.org/10.17957/ijab/15.0108

OPEN ACCESS

(c) (2)
The journal offers free, immediate, and unrestricted access to peer-reviewed research and scholarly work. Users are allowed to read, download, copy, distribute, print, search, or link to the full texts of the articles, or use them for any other lawful purpose, without asking prior permission from the publisher or the author.

License - Articles published in Notulae Botanicae Horti Agrobotanici Cluj-Napoca are Open-Access, distributed under the terms and conditions of the Creative Commons Attribution (CC BY 4.0) License. (c) Articles by the authors; UASVM, Cluj-Napoca, Romania. The journal allows the author(s) to hold the copyright/to retain publishing rights without restriction. 